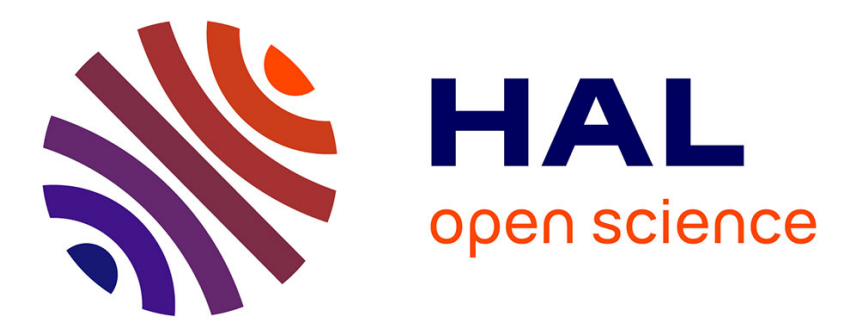

\title{
Variations in seasonal (not mean) temperatures drive rapid adaptations to novel environments at a continent scale
}

\author{
Jean-claude Tourneur, Joël Meunier
}

\section{- To cite this version:}

Jean-claude Tourneur, Joël Meunier. Variations in seasonal (not mean) temperatures drive rapid adaptations to novel environments at a continent scale. Ecology, 2020, 101 (4), pp.e02973. 10.1002/ecy.2973 . hal-02471098

\section{HAL Id: hal-02471098 \\ https://hal-univ-tours.archives-ouvertes.fr/hal-02471098}

Submitted on 20 May 2020

HAL is a multi-disciplinary open access archive for the deposit and dissemination of scientific research documents, whether they are published or not. The documents may come from teaching and research institutions in France or abroad, or from public or private research centers.
L'archive ouverte pluridisciplinaire HAL, est destinée au dépôt et à la diffusion de documents scientifiques de niveau recherche, publiés ou non, émanant des établissements d'enseignement et de recherche français ou étrangers, des laboratoires publics ou privés. 
1 Variations in seasonal (not mean) temperatures drive rapid adaptations to

\section{2 novel environments at a continent-scale}

3 Running title: Climate adaptation in earwigs

4 Jean-Claude Tourneur ${ }^{1}$, Joël Meunier ${ }^{2 *}$

$5 \quad \quad{ }^{1}$ Département des Sciences biologiques, Université du Québec à Montréal 141. Avenue du

6 Président-Kennedy, Montréal, Québec, H2X 1Y4, Canada.

7 Email: jc.tourneur@nb.sympatico.ca

$8 \quad{ }^{2}$ Institut de Recherche sur la Biologie de l'Insecte (IRBI), UMR 7261, CNRS, Université de

9 Tours, Tours, France.

10 Email: joel.meunier@univ-tours.fr $\_$ORCID: 0000-0001-6893-2064

$11 *$ Corresponding author. 


\section{ABSTRACT}

13 The recent development of human societies has led to major, rapid and often inexorable

14 changes in the environment of most animal species. Over the last decades, a growing number

15 of studies formulated predictions on the modalities of animal adaptation to novel or changing

16 environments, questioning how and at what speed animals should adapt to such changes,

17 discussing the levels of risks imposed by changes in the mean and/or variance of temperatures

18 on animal performance, and exploring the underlying roles of phenotypic plasticity and genetic

19 inheritance. These fundamental predictions, however, remain poorly tested using field data.

20 Here, we tested these predictions using a unique continental-scale data set in the European

21 earwig Forficula auricularia L, a univoltine insect introduced in North America one century

22 ago. We conducted a common garden experiment, in which we measured 13 life-history traits

23 in 4158 field-sampled earwigs originating from 19 populations across North America. Our

24 results first demonstrate that 10 of the 13 measured life-history traits are associated with two

25 sets of variations in seasonal temperatures, i.e. winter-summer and autumn-spring. We found,

26 however, no association with the overall mean monthly temperatures of the invaded locations.

27 Furthermore, our use of a common garden setup reveals that the observed patterns of variation

28 in earwigs' life-history traits are not mere plastic responses to their current environment, but

29 are either due to their genetic background and/or to the environmental conditions they

30 experienced during early life development. Overall, these findings provide continent-scale

31 support to the claims that adaptation to thermal changes can occur quickly (in less than 100

32 generations), even in insects with long life cycles, and emphasize the importance of variation

33 in seasonal temperature over mean population temperatures in climate adaptation.

34 Keywords: Temperature, Adaptation, Reproductive strategy, Climate change, Invasion,

35 Dermaptera 
37 Adaptation to novel and changing environments is a keystone in our current understanding of species distribution, abundance and evolution (Holt 1990). Over the last century, the

39 development of human activities has led to rapid and often inexorable changes in the 40 environment of many living organisms (Parmesan 2006). These changes occur, for instance, 41 due to human trade and transit, which increasingly favours the transport (invasion) of a large number of animal and plant species out of their native area (Hulme 2009), and possibly bring them to novel environments with unfamiliar biotic and/or abiotic properties (Jeschke and Strayer 2005). These changes can also occur in the native area of these organisms due to the global climate change, a phenomenon that has accelerated over the last decades and now reaches an unprecedented speed (Meehl and Tebaldi 2004, Williams et al. 2007). Because the extent and multiplicity of these rapid environmental changes challenge the ability of resident populations to track them and adapt their life histories accordingly, understanding the nature of animals' adaptation to novel and changing environment is considered a critical, ongoing and challenging question in ecology (Parmesan 2006, Hill et al. 2016, 2019, Courchamp et al. 2017).

Among the multiple parameters that can vary when a species is exposed to a novel or changing environment, the mean and seasonal temperatures can be particularly critical. This is because the severity and duration of changes in the temperatures experienced by an individual during its entire or a specific period of its life cycle can alter a great number of its life history traits and ultimately modify its own fitness. For instance, extended winter durations or exposure to warmer environmental conditions can shape the size and time of first reproduction (Fretwell 1972, Altizer et al. 2006), the duration of foetal development and levels of immune activity (Körner et al. 2018, Zhang et al. 2019), as well as the mobility, morphology and metabolism of individuals (Adamczewski et al. 1993, Danks 2000, Polidori et al. 2019). 
Over the last decades, a great number of modelling and theoretical approaches have

62 been developed to better understand the nature and extent of animals' adaptation to novel 63 temperatures (Parmesan 2006). These studies formulated key predictions on how and at what 64 speed animals should adapt to such changes, on the respective importance of an increase in the 65 overall mean temperature and/or seasonality of a population on animal performance, as well as on the underlying roles of phenotypic plasticity and genetic inheritance in adaption (Nylin and

67 Gotthard 1998, Kingsolver et al. 2013, Paaijmans et al. 2013, Gilbert et al. 2014, Merilä and Hendry 2014, Levis and Pfennig 2016, Williams et al. 2017, Corl et al. 2018, Fox et al. 2019, Rohner et al. 2019). For instance, these studies suggest that adaptation to climate change should be rapid in organisms with fast development and short life-cycles, as found in many arthropods, whereas it should be slower in organisms exhibiting delayed development and long life-cycles, as found in many vertebrates. Species should also be less sensitive to changes in seasonality compared to changes in overall mean temperatures when they are endotherms and/or when their entire life-cycle occur within a single season, whereas the opposite pattern is expected when they are ectotherms and/or have a life-cycle encompassing several seasons. Finally, phenotypic plasticity is often considered a keystone of rapid adaptation to environmental changes, whereas fixed and inherited patterns of adaptation are often thought to secondarily derive from the canalization of ancestral plastic variation (Chevin et al. 2010).

Although central in our current understanding of animal's adaptation to novel temperatures, these fundamental predictions remain poorly tested in the field (Janion-

81 Scheepers et al. 2017, Blanckenhorn et al. 2018). This is probably because such field data are difficult to collect, as it typically requires measuring variation in life-history traits across multiple natural populations, over several years, and under different climates. A powerful alternative consists in using field data of introduced species that recently invaded large geographic areas exhibiting a broad diversity of thermal constraints (Huey et al. 2000, Bellard 
87 is one of these species. This insect exhibits a broad native range extending across Europe, Asia and northern Africa (Lamb and Wellington 1975) from which it has been introduced to Australia, New Zealand, East Africa, East Indies, Tasmania and North America (Frank 1918,

90 Guillet et al. 2000, Quarrell et al. 2018, Hill et al. 2019). Its presence in North America was

91 first reported on the Pacific coast in Seattle (WA) in 1907, and then on the Atlantic coast in Newport (RI) in 1911 and in Vancouver (BC) in 1919 (Crumb et al. 1941). From these introductory foci (Figure 1), historical data suggests that $F$. auricularia first spread along the coasts to cover areas ranging from British Columbia to California and from Newfoundland to South Carolina, and then spread to the interior of the continent in both United States of America and Canada (Crumb et al. 1941, Tourneur 2017)(Historical records are detailed in Appendix S1: Table S1). Given that this species produces only one generation per year (Tourneur and Gingras 1992, Meunier et al. 2012), these data reveal that its successful colonization of North America and thus its adaptation to a broad diversity of thermal environments occurred in less than 100 generations. responded to the different thermal environments encountered during their North American invasion over the last century, i.e. in less than 100 generations. Because the univoltine life cycle of the European earwig encompasses all seasons and temperatures (Lamb 1976, Meunier et al. 2012), it has long been thought that annual mean temperatures and/or seasonality could be major constraints in its invasive success (Vancassel 1984, Hill et al. 2019). However, it remains unclear whether this species can mitigate these thermal constraints, and whether it does so by adapting its life cycle and life-history traits (Ratz et al. 2016, Tourneur 2018). 
111 traits), 2) identified the thermal constraints to which they adapted and 3) investigated the role

112 of phenotypic plasticity in this adaptation. From 1988 to 1995 , we field-sampled individuals

113 originating from 19 populations located from the East to the West coasts, maintained them

114 under standard laboratory conditions and measured the properties of the $1^{\text {st }}$ and $2^{\text {nd }}$ (generally

115 terminal) clutches produced by each female in terms of egg laying date, egg number, egg

116 development time and number of newly hatched larvae. We also recorded the reproductive

117 strategy of the females (iteroparity versus semelparity), their reproductive outcome (total

118 number of eggs and larvae produced over lifetime), as well as the experimental survival

119 duration of the field-sampled males and females. To identify which thermal constraints the

120 tested earwigs adapted to, we tested whether our measurements could be explained by the

121 results of a principal component analyses (PCA) of the mean monthly temperatures of each

122 population. This process characterizes patterns of variation among populations' temperatures

123 without a priori definitions of their associations, i.e. without predetermining the focus on

124 overall mean temperatures and/or variation of temperatures between seasons or months.

125 Generating these temperature predictor variables without a priori definitions of their 126 composition was important, as both temperatures' average and seasonal variability can shape

127 animal life histories (Kingsolver et al. 2013). If $F$. auricularia individuals adapted their life-

128 cycle and life-history traits to the mean temperatures and/or seasonal temperature variation of

129 the population in which they have been sampled (and if this adaptation is determined by their

130 genetic background and/or early life experience), we predict these traits to covary with the overall mean temperatures and/or variation in seasonal temperatures of their population (i.e. all sampled populations should show different performance in the common garden). Conversely,

133 if earwig life-history traits are independent of the thermal environment of the population in

134 which they have been sampled (i.e. no adaptation) and/or are plastic to their current thermal

135 environment, we predict no apparent association between the traits measured in our field- 
sampled individuals and the seasonal temperature variation of their populations (i.e. all sampled populations should show similar performance in the common garden).

\section{MATERIAL AND METHODS}

\section{Earwig biology}

140 The life cycle of the European earwig generally starts with the emergence of new adults in late

141 spring to early July (with variation among populations). These adults form groups of up to several hundred individuals, in which both males and females typically mate with several partners (Weiß et al. 2014, Sandrin et al. 2015, Tourneur 2017). Females then burrow in the ground from mid fall to early winter and build a nest where they lay their first clutch of eggs. After egg laying, females stop their foraging activity and provide extensive forms of egg care until hatching (Gingras and Tourneur 2001, Boos et al. 2014, Koch and Meunier 2014, Thesing et al. 2015, Diehl and Meunier 2018, Körner et al. 2018). The eggs of this first clutch hatch in spring and mothers remain with their newly hatched larvae for several weeks, during which mothers provide larvae with multiple forms of care (Gingras and Tourneur 2001, Kölliker et al. 2015, Kramer et al. 2015) and larvae exhibit forms of sibling cooperation (Falk et al. 2014, Kramer et al. 2015, Kramer and Meunier 2016, Körner et al. 2016). A few weeks later, the family unit is naturally disrupted. While larvae continue their development to adults in new social groups, some females produce a second clutch of eggs (i.e. iteroparous as compared to semelparous females), which will also receive pre- and post-hatching care and will hatch in late spring (Lamb and Wellington 1975, Meunier et al. 2012, Ratz et al. 2016). All females generally die during the following summer (Albouy and Caussanel 1990). 
habitations in its newly colonized area (Crumb et al. 1941, Lamb and Wellington 1975, Walker

160 et al. 1993, Quarrell et al. 2016, 2018). Moreover, this species has been suggested to have partly

161 drove the decline of threatened and endangered invertebrates in America, such as the El

162 Segundo Blue Butterfly Euphilotes bernardino allyni and the Valley Elder-berry Longhorn

163 Beetle Desmocerus californicus dimorphus (Quarrell et al. 2018).

\section{Earwig sampling and laboratory rearing}

165 All F. auricularia individuals were collected over 7 years among 19 natural populations located across North America (Figure 1, Table 1). These individuals were mostly collected as adults using wooden traps (Tourneur 2018) between July and August, and were immediately setup in

168 glass containers (Mason Jars Company, Erie, Pennsylvania, United States of America) in groups of 20 to 30 individuals. These containers received two sheets of creased toilet paper as resting places for earwigs, and were then transported to the laboratory in Montreal, Canada. Upon their arrival, containers were deposited in a shelf covered by a shelter and maintained under the natural outdoor conditions of Montreal. During their transport and outdoor maintenance, containers received an ad libitum amount of carrots and pollen as a food source for earwigs, and were supplied with water by means of a cotton pad regularly soaked in water. This setup allowed earwigs to perform non-controlled mating and to live in groups, which is similar to their natural living conditions (Weiß et al. 2014, Sandrin et al. 2015, Kohlmeier et al. 2016, Körner et al. 2018).

One to two months later (between the $7^{\text {th }}$ and the $19^{\text {th }}$ day of October of each year), we used 4158 of these field-sampled individuals to set up 2079 mating pairs (from 17 to 356 pairs per population, see Table 1), in which we subsequently measured 13 life-history traits (see below). These pairs were set up in Petri dishes (diameter $10 \mathrm{~cm}$ ) lined with a thin layer of moist sand, and in which food was changed and substrate humidified once a week. Each Petri dish was then transferred in a climate chamber and then maintained at $10 \pm 1{ }^{\circ} \mathrm{C}$, a temperature 
close to the overall median temperature of the 19 sampled populations (i.e. $9.5^{\circ} \mathrm{C}$, see Appendix

185 S1: Table S2). Food was removed at egg laying to mimic the natural end of earwigs' foraging 186 activity (Kölliker 2007). At egg hatching, we discarded all newly emerged larvae from the

187 experiments to trigger a novel ovarian cycle in the mothers and allow their production of a 188 subsequent clutch (Vancassel and Foraste 1980, Meunier et al. 2012). We then maintained the 189 pairs under the rearing conditions described above until our experiment ended, i.e. either one 190 year after the beginning of our laboratory setup or at the death of the adult males and females. 191 Overall, 3927 of the $4158(94.4 \%)$ tested individuals died within the year following the 192 beginning of our experiments, a value in line with previous data on $F$. auricularia lifespan 193 (Albouy and Caussanel 1990). Note that recent studies revealed that North American $F$. auricularia encompasses two genetic subspecies with no apparent mixing of their populations

195 (Wirth et al. 1998, Quarrell et al. 2018, Tourneur 2018). Although these subspecies were not considered in our analyses (our data were collected before the publication of these genetic 197 analyses), the continuous distribution (unimodal data) of the life history traits measured across 198 populations (Figures 2 to 4) suggests an absence of subspecies-specific values regarding these measurements. The potential co-occurrence of the two subspecies in our data set is thus unlikely to bias our study and its main conclusions.

\section{Measurements of the life-history traits}

202 For each mating pair, we measured 13 life-history traits encompassing the properties of the resulting $1^{\text {st }}$ and $2^{\text {nd }}$ clutches (when present), the reproductive strategy and reproductive outcomes of each female, as well as the experimental survival duration of both field-sampled males and females. These properties were obtained by recording the date of egg production, counting the number of eggs produced, calculating the duration of egg development until hatching (in days) and finally counting the number of larvae at egg hatching in both $1^{\text {st }}$ and $2^{\text {nd }}$ clutches (when present). The reproductive strategies and reproductive outcomes of females 
were obtained by recording whether they were semelparous or iteroparous (i.e. produced one

210 or two clutches in their lifetime, respectively), and by counting the total number of eggs and

211 larvae produced per female during their lifetime. Finally, we measured the experimental

212 survival duration of adults by counting the number of days each male and female survived after

213 October $1^{\text {st }}$ of the year of field sampling. Although our measurement of survival duration does

214 not necessarily reflect adults longevity, as individuals could have different ages at field

215 sampling (see discussion), it nevertheless provides important insights into the period at which

216 males and females of each population die during the year. Note that $8.1 \%$ and $5.4 \%$ females

217 from Santa Cruz and Asheville, respectively, produced a third clutch. This third clutch was not

218 considered in the present study, as our experiment ended before their hatching.

\section{Extraction of mean and seasonal temperatures of each population}

220 We extracted the mean monthly temperature of the 19 studied populations using their GPS coordinates (Table 1) and the Worldclim database v2.0 (http://www.worldclim.org/) with a spatial resolution of 30 seconds. The mean temperatures provided by the Worldclim database are calculated over 30 years, from 1970 to 2000. To reduce dimensionality of co-varying temperatures in our data set while characterizing the variation in seasonal temperature of each population without a priori definitions of their composition, we then conducted a Principal (PCs), out of which we retained the first three PCs (total variance explained $=98.6 \%$, Table 2).

The first component (PC1) was positively loaded by almost all monthly temperatures, therefore positively reflecting the overall mean temperature of a population. The second component

231 (PC2) revealed variation in seasonality between February on one hand, and June, July, and

232 August on the other hand. In particular, high values of PC2 reflected populations with cold 233 February (winter) and warm summer, whereas small values of PC2 reflected populations with 
warm February (winter) and cold summer. Finally, the third component (PC3) captured variation in seasonality between October and November on one hand, and April and May on the other hand. High values of PC3 therefore characterized populations with cold autumn and warm spring, whereas small values of PC3 characterized populations with warm autumn and cold spring.

\section{Statistical analyses}

240 To test whether F. auricularia adapt their life-cycle and life-history traits to North American

241 temperatures, we conducted a series of 12 linear models (LM in R) and one generalized linear 242 model (GLM in R) - see Table 3. In the 12 LMs, the three selected PCs and their interactions 243 were entered as explanatory variables (PC1, PC2 and PC3), whereas the response variable was 244 either egg laying date, egg number, egg development time and larvae number for the $1^{\text {st }}$ or $2^{\text {nd }}$ clutches (for a total of $8 \mathrm{LMs}$ ), the total number of eggs or larvae produced, or the survival duration of males or females. Note that both egg laying date and adult survival duration were calculated using October $1^{\text {st }}$ as day 0 . In the GLM, the response variable was the ratio of iteroparous females per population, which was entered using the command $c b i n d$ in $\mathrm{R}$ (to weight each ratio by the sample size of its population) and fitted to a binomial error distribution corrected for overdispersion. In all our statistical models, the response variables were the mean values of each measured trait per population. They were also checked for homoscedasticity and normality of residuals, as well as simplified stepwise by removing all non-significant interaction terms (all $\mathrm{P}>0.05$ ). To correct for inflated Type-I errors due to multiple testing (and provide an experiment-wide Type I error rate of 5\%), all $P$-values were adjusted using False Discovery Rate (FDR) correction (Benjamini and Hochberg 1995). All analyses were 


\section{RESULTS}

259 The 19 study sites greatly varied in their mean and seasonal variation of temperature (Appendix

260 S1: Table S2), as well as in the mean values of the 13 traits measured in their sampled 261 individuals (Figures 2 to 4; Appendix S1: Tables S3 to S5). Mean monthly temperatures overall 262 ranged from $22.9^{\circ} \mathrm{C}$ (July in Saluda) to $-10.1^{\circ} \mathrm{C}$ (January in Montreal), while thermal amplitudes over a year ranged from $30.7^{\circ} \mathrm{C}$ (Montreal) to $7.9^{\circ} \mathrm{C}$ (Santa Cruz). For the traits measured in the $1^{\text {st }}$ clutches, the mean \pm SE dates of egg production ranged from $47.8 \pm 0.8$ to $132.6 \pm 3.3$ days after the $1^{\text {st }}$ of October, the mean \pm SE number of eggs per clutch from 23.2 \pm 1.9 to $66.0 \pm 2.3$, the mean \pm SE egg development time from $42.2 \pm 1.0$ to $71.4 \pm 0.8$ days and the mean \pm SE number of larvae per clutch from $11.6 \pm 2.0$ to $44.8 \pm 3.2$. For the $2^{\text {nd }}$ clutches, the mean \pm SE dates of egg production ranged from 142.0 to $248.2 \pm 5.3$ days after the $1^{\text {st }}$ of October, the mean \pm SE number of eggs from 14.0 to $38.4 \pm 1.7$, the mean \pm SE egg development time from $10.0 \pm 3.0$ to $63.7 \pm 4.6$ days and the mean \pm SE number of larvae from 0 to $17.7 \pm 8.8$. Finally, the total number of eggs \pm SE produced ranged from $28.1 \pm 2.6$ to 83.4 \pm 2.9 , the total number of larvae $\pm \mathrm{SE}$ produced from $13.0 \pm 2.2$ to $46.3 \pm 3.5$, the proportion of iteroparous females from 0 to $70.8 \%$, and the mean survival duration $\pm \mathrm{SE}$ of males and females from $82.0 \pm 15.4$ to $299.8 \pm 8.6$ days and from $146.0 \pm 4.7$ to $322.5 \pm 7.6$ days after the $1^{\text {st }}$ of October, respectively.

Of the 13 measured traits, 10 varied together with the seasonal temperature variation of the population of origin (Table 3). Five of these 10 traits were exclusively associated with PC2

278 (February-summer temperatures), two traits were exclusively associated with PC3 (autumnspring temperatures), and three traits were associated with both PC2 and PC3. By contrast, no traits were associated with PC1 (overall mean temperatures). The associations with PC2 revealed that populations with cold February and warm summers (high PC2 values) had females that produced their $1^{\text {st }}$ clutch of eggs earlier and these eggs had longer development 
time compared to populations exhibiting warm February and cold summers (low PC2 values,

284 Figure 2). Similarly, females from the former populations were less likely to produce a second 285 clutch (i.e. to be iteroparous, Figure 3) and when they did so, their $2^{\text {nd }}$ clutch eggs were less 286 numerous (Figure 3) and showed longer development time (Figure 3). Moreover, females and 287 males from populations with cold February and warm summers lived fewer days compared to 288 adults from warm February and cold summers (Figure 4). On the other hand, the effects of PC3 reveal that populations exhibiting cold autumns and warm springs (high PC3 values) had

290 females that produced their $1^{\text {st }}$ clutch of eggs later in the season and these eggs were less

291 numerous compared to females from populations with warm autumns and cold springs (low

292 PC3 values, Figure 2). Females from populations with high PC3 values also had $2^{\text {nd }}$ clutch eggs that exhibited a shorter developmental time (Figure 3), they produced an overall lower number of eggs (Figure 4) and had males with a longer survival duration (Figure 4). By contrast, PC1, PC2 and PC3 did not shape the number of $1^{\text {st }}$ clutch larvae, as well as their total number and the dates of $2^{\text {nd }}$ clutch egg laying (Figures 2, 3 and 4; Table 3).

\section{DISCUSSION}

298 In this study, we demonstrate that the successful invasion of the European earwig across North 299 America came with multiple changes in their life-history traits, and that these changes are associated with seasonal variation in the temperatures - but not with overall mean temperatures - of the invaded areas. In particular, our data from 19 populations revealed an association

302 between seasonal temperature variation and females' timing of first reproduction, reproductive strategy and investment into egg production, as well as between seasonal temperature variation and the experimental survival duration of both males and females. By contrast, we found no association between seasonal temperature variation and both the timing of second clutch reproduction and the total number of larvae produced per female. 
came from populations facing warm summers and/or warm autumns (PC2 and PC3, respectively), and were less likely to produce a second clutch in populations with cold

310 February. A plastic response to warm temperatures on egg laying date could be expected in

311 nature: adult earwigs typically develop and mate during summer and autumn, so that warm temperatures during these seasons could accelerate their reproductive physiology (as shown in

313 other insect species, Singh et al., 2018) and thus accelerate egg laying (Tourneur 2018).

314 Similarly, cold Februaries might slow down the development of $1^{\text {st }}$ clutch eggs and thus extend

315 the corresponding period of egg care. This, in turn, might inhibit females' physiological

316 transformation to produce a second clutch (Vancassel 1984, Gingras and Tourneur 2001,

317 Tourneur 2018, Körner et al. 2018). However, our results were obtained under common garden

318 conditions, which reveals that the observed effects of the variation in seasonal temperature on

319 egg laying dates are not a plastic response to their current environment, but are either due to

320 the environment experienced during their early life development (i.e. before field sampling),

321 or due to an inherited basis that possibly emerged through canalization (Nylin and Gotthard

322 1998, Van Buskrik and Steiner 2009). It has been proposed that traits tightly linked to fitness are more strongly canalized due to past stabilizing selection (Falconer 1990). Our findings may therefore suggest that the observed patterns in the timing of first reproduction and females' reproductive strategy may have first emerged as a plastic response to the thermal constraints of the different localities, then diverged between populations through canalization and ultimately become inherited traits - all this in a maximum of 100 generations. Further experiments with naïve individuals would be required to rule out an effect of early life experience. production, but not with lifetime larvae production. In particular, the total number of eggs produced per female decreased with decreasing autumn temperatures, whereas this association 
vanished with larvae number. This apparent discrepancy suggests that eggs from populations

333 with the warmest autumns suffered higher mortality during development. A first explanation

334 of this phenomenon could be that these eggs are of a lower quality and/or that their mothers

335 were less efficient in egg care, a process that is essential to ensure egg development until

336 hatching in earwigs (Boos et al. 2014, Van Meyel et al. 2019). Whereas both effects should be

337 tested in future studies, previous results may suggest that a population-specific efficiency in

338 egg care is unlikely in this species, as a previous study showed that maternal investment in

339 post-hatching care is not population-specific, at least in Europe (Ratz et al. 2016). Another

340 explanation is that females consumed a larger proportion of their clutch in populations with the

341 warmest compared to the coldest autumns. Filial egg consumption is a common phenomenon

342 in insects (Elgar and Crespi 1992) and it has been recently reported in several Dermapteran

343 species, such as the species studied here (Koch and Meunier 2014, Van Meyel et al. 2019) and

344 the maritime earwig Anisolabis maritima Bonelli (Miller and Zink 2012). In the European

345 earwig, this phenomenon has been proposed to reflect an adaptive strategy to limit female

346 weight loss during the period of egg care (i.e. when they stop all other foraging activities) and

347 by doing so, to reallocate resources into post-hatching care and/or into a $2^{\text {nd }}$ oogenesis cycle

348 (Koch and Meunier 2014, Tourneur 2018). Given that females lay eggs earlier in populations

349 with the warmest autumns, this increased egg consumption could be an adaptive strategy to

350 limit the cost of tending newly hatched offspring earlier in the season (middle of winter) when

351 food sources are scarce or absent. If this hypothesis holds true, it would suggest that filial egg

352 cannibalism could be a strategy that $F$. auricularia females have evolved to better cope with

353 warmer autumns.

In addition to the above findings, our results show that the survival duration of both males and females was associated with the seasonal temperature variation of the population of origin. In particular, females' and males' survival duration decreased together with warm 
summers (and cold Februaries), while male's survival duration also decreased with warm on their date of egg laying and/or egg hatching. We showed that females from populations

360 facing warm summers are the first to lay their eggs. Individuals from these populations might thus have been the oldest at the date of our field sampling, therefore leading to the shortest survival duration in our subsequent experiment. Surprisingly, there was a sex-specific effect of spring (and autumn) temperatures on adult survival duration: males lived up to two times longer in populations with warm compared to cold springs (as well as cold compared to warm autumns), whereas this effect was absent in females. This finding may reflect sex-specific sensitivity to high temperatures in terms of, for instance, physiology or expression of costly behaviors. Whereas some physiological traits are known to be sex-specific in this species (Kohlmeier et al. 2016, Vogelweith et al. 2017), further studies should explore the effects of temperature on the observed differences. Notwithstanding its underlying mechanisms, the long survival duration of males in warm spring populations opens scope for these males to mate with females of the subsequent generation, as well as for a possible involvement of fathers into larva care - a phenomenon reported in other insect species (Smiseth 2014). These two processes remain unknown in the European earwig, but they could be of central importance in their successful adaptation to climate change.

All our results are based on a common garden experiment, a method that is often considered a powerful tool to disentangle the roles of phenotypic plasticity and genetic background on adaptation (Franks et al. 2014, Stoks et al. 2014, Blanckenhorn et al. 2018). Individuals reared under a common environment are typically expected to exhibit homogenized life-history traits if adaptation is the outcome of phenotypic plasticity, whereas they should exhibit population-specific traits otherwise. Our results are in line with the latter process for the great majority of the measured traits (10 out of 13), therefore suggesting that the observed 
associations between variation in seasonal temperature and life-history traits do not stem from a plastic response to their current environment. Nevertheless, common garden experiments can also have some limits: they do not necessarily prevent maternal and grand maternal effects, they cannot preclude the possibility of genotype-by-environment interactions on the measured life-history traits, and they are poorly efficient at shedding light on the multiple facets of plasticity (e.g. some traits can be partially plastic, the plastic responses can vary in intensity and slope, and plasticity may become apparent only after certain thresholds)(Franks et al. 2014, Merilä and Hendry 2014, Stoks et al. 2014, Bodensteiner et al. 2019). Concluding on the absence or limited role of plasticity in earwigs' adaptation to seasonality therefore needs further empirical works. These works should, for instance, explore its pattern using lab-generations of each population to control for potential maternal effects, or investigate the multiple facets of adaptation under different common garden conditions (e.g. using different temperatures) (Bodensteiner et al. 2019) and if an apparent plasticity emerge, they should demonstrate its adaptive value.

To conclude, our results demonstrate that the spread of the European earwigs across

397 North America came with important changes in their life-history traits and life cycle, and that these changes emerged in a maximum of 100 generations. Whereas we show that some of these changes are by-products of novel thermal constraints (timing of first reproduction and female iteroparity), we reveal that others are likely to reflect adaptive strategies to cope with different autumn temperatures (egg production and the possibility of egg cannibalism). Overall, these

402 findings emphasize that adaptation of an insect with a relatively long life-cycle does not necessarily operate in response to the overall mean temperatures of the invaded environments, but in response to their seasonality and/or mean temperature at a specific time of their lifecycle. Whether the reported adaptations are the product of population-differences in energetic/metabolic constraints experienced by adults during their early development (Wong 
and Kölliker 2014, English et al. 2016), and/or the product of an inherited genetic basis that

408

409

410

411

412

413

414

415

416

417

418

419

420

421

422

423

424

425

426

427

428 varies with seasonal temperature variation (Levis and Pfennig 2016; Corl et al. 2018; Fox et al. 2019), as well as whether these adaptations are similar across its worldwide distribution (Frank 1918, Guillet et al. 2000, Huey et al. 2000, Quarrell et al. 2018, Hill et al. 2019) will be investigated in future studies. On a more general level, our findings emphasize that studying invasive species can provide unique data sets to empirically and comprehensively test general predictions on animals' responses to novel environmental conditions and climate change (Gilbert et al. 2014, Merilä and Hendry 2014, Levis and Pfennig 2016, Hulme 2017, Fox et al. 2019, Rohner et al. 2019), and therefore call for their open access to the entire research community - a timely task to which the present study contributes.

\section{ACKNOWLEDGMENTS}

This work is dedicated to the memory of Noelle Tourneur, for her constant support through JCT career. We thank Maximilian Körner, Franck Dedeine and Sylvain Pincebourde, as well as Eric Gangloff, Ben Phillips and Fabien Aubret (Peer Community in Evolutionary Biology referees and recommenders, respectively) for their comments on a previous version of this manuscript. Note that a former version of this manuscript has been recommended by Peer Community in Evolutionary Biology. We also would like to thank Jean Gingras for his help during laboratory observations and samplings, as well as Michel Vancassel and Maryvonne Forasté for their help in the late 1980s. JCT designed the experiment, conducted field samplings, and run the experiments. JM analysed the data and wrote the first version of the manuscript. The final manuscript was commented and corrected by all authors. The authors declare that they have no financial conflict of interest with the content of this article. 
430 Adamczewski, J. Z., R. J. Hudson, and C. C. Gates. 1993. Winter Energy-Balance and

431 Activity of Female Caribou on Coats-Island, Northwest-Territories - the Relative Importance

432 of Foraging and Body Reserves. Canadian Journal of Zoology-Revue Canadienne De

433 Zoologie 71:1221-1229.

434 Albouy, V., and C. Caussanel. 1990. Dermaptères ou perce-oreilles. Fédération Francaise des 435 Sociétés de Sciences Naturelles, Paris.

436 Altizer, S., A. Dobson, P. Hosseini, P. Hudson, M. Pascual, and P. Rohani. 2006. Seasonality 437 and the dynamics of infectious diseases. Ecology Letters 9:467-484.

438 Bellard, C., B. Leroy, W. Thuiller, J. F. Rysman, and F. Courchamp. 2016. Major drivers of 439 invasion risks throughout the world. Ecosphere 7:1-14.

440 Benjamini, Y., and Y. Hochberg. 1995. Benjamini Y, Hochberg Y. Controlling the false 441 discovery rate: a practical and powerful approach to multiple testing. Journal of the Royal 442 Statistical Society B 57:289-300.

443 Blanckenhorn, W. U., S. S. Bauerfeind, D. Berger, G. Davidowitz, C. W. Fox, F. Guillaume, 444 S. Nakamura, K. Nishimura, H. Sasaki, R. C. Stillwell, T. Tachi, and M. A. Schäfer. 2018. 445 Life history traits, but not body size, vary systematically along latitudinal gradients on three 446 continents in the widespread yellow dung fly. Ecography 41:2080-2091.

447 Bodensteiner, B. L., D. A. Warner, J. B. Iverson, C. L. Milne-Zelman, T. S. Mitchell, J. M. 448 Refsnider, and F. J. Janzen. 2019. Geographic variation in thermal sensitivity of early life 449 traits in a widespread reptile. Ecology and Evolution 9:2791-2802.

450 Boos, S., J. Meunier, S. Pichon, and M. Kölliker. 2014. Maternal care provides antifungal 451 protection to eggs in the European earwig. Behavioral Ecology 25:754-761.

452 Van Buskrik, J., and U. K. Steiner. 2009. The fitness costs of developmental canalization and 453 plasticity. Journal of Evolutionary Biology 22:852-860. 
Chevin, L.-M., R. Lande, and G. M. Mace. 2010. Adaptation, plasticity, and extinction in a

455 changing environment: Towards a predictive theory. PLoS Biology 8:e1000357.

456 Corl, A., K. Bi, C. Luke, A. S. Challa, A. J. Stern, B. Sinervo, and R. Nielsen. 2018. The

457 genetic basis of adaptation following plastic changes in coloration in a novel environment.

458 Current Biology 28:2970-2977.e7.

459 Courchamp, F., A. Fournier, C. Bellard, C. Bertelsmeier, E. Bonnaud, J. M. Jeschke, and J.

460 C. Russell. 2017. Invasion Biology: Specific Problems and Possible Solutions. Trends in

$461 \quad$ Ecology and Evolution 32:13-22.

462 Crumb, S. E., P. M. Eide, and A. E. Bonn. 1941. The European earwig. Page USDA

463 Technical Bulletin. USDA Technical Bulletin 766.

464 Danks, H. V. 2000. Dehydration in dormant insects. Journal of Insect Physiology 46:837465852.

466 Diehl, J. M., and J. Meunier. 2018. Surrounding pathogens shape maternal egg care but not 467 egg production in the European earwig. Behavioral Ecology 29:128-136.

468 Elgar, M. A., and B. J. Crespi. 1992. Cannibalism: ecology and evolution among diverse 469 taxa. Oxford University Press, Oxford.

470 English, S., T. W. Fawcett, A. D. Higginson, P. C. Trimmer, and T. Uller. 2016. Adaptive use 471 of information during growth can explain long-term effects of early Life experiences. The 472 American Naturalist 187:620-632.

473 Falconer, D. S. 1990. Selection in different environments: effects on environmental 474 sensitivity (reaction norm) and on mean performance. Genetical Research 56:57.

475 Falk, J., J. W. Y. Wong, M. Kölliker, and J. Meunier. 2014. Sibling cooperation in earwig 476 families provides insights into the early evolution of social life. The American Naturalist 
478 Fox, R. J., J. M. Donelson, C. Schunter, T. Ravasi, and J. D. Gaitán-Espitia. 2019. Beyond 479 buying time: the role of plasticity in phenotypic adaptation to rapid environmental change. 480 Philosophical Transactions of the Royal Society B: Biological Sciences 374:20180174.

481 Frank, L. M. 1918. Notes from tasmania. J Econ Ent 11:472-475.

482 Franks, S. J., J. J. Weber, and S. N. Aitken. 2014. Evolutionary and plastic responses to 483 climate change in terrestrial plant populations. Evolutionary Applications 7:123-139.

484 Fretwell, J. 1972. Populations in a Seasonal Environment. Page (P. U. Press, Ed.). Princeton, 485 NJ.

486 Gilbert, B., H. S. Greig, K. S. McCann, M. I. O’Connor, J. P. DeLong, C. D. G. Harley, V. 487 Savage, T. D. Tunney, and D. A. Vasseur. 2014. Increased temperature variation poses a 488 greater risk to species than climate warming. Proceedings of the Royal Society B: Biological 489 Sciences 281:20132612-20132612.

490 Gingras, J., and J.-C. Tourneur. 2001. Timing of adult mortality, oviposition, and hatching 491 during the underground phase of Forficula auricularia (Dermaptera: Forficulidae). Canadian 492 Entomologist 133:269-278.

493 Guillet, S., N. Josselin, and M. Vancassel. 2000. Multiple introductions of the Forficula 494 auricularia species complex (Dermaptera: Forficulidae) in eastern North America. Canadian 495 Entomologist 132:49-57.

496 Hill, M. P., M. Binns, P. A. Umina, A. A. Hoffmann, and S. Macfadyen. 2019. Climate, 497 human influence and the distribution limits of the invasive European earwig, Forficula 498 auricularia, in Australia. Pest Management Science 75:134-143.

499 Hill, M. P., S. Clusella-Trullas, J. S. Terblanche, and D. M. Richardson. 2016. Drivers, 
501 Holt, R. D. 1990. The microevolutionary consequences of climate change. Trends in Ecology 502 and Evolution 5:590-596.

503 Huey, R. B., G. W. Gilchrist, M. L. Carlson, D. Berrigan, and L. Serra. 2000. Rapid evolution 504 of a geographic cline in size in an introduced fly. Science 287:308-309.

505 Hulme, P. E. 2009. Trade, transport and trouble: Managing invasive species pathways in an 506 era of globalization. Journal of Applied Ecology 46:10-18.

507 Hulme, P. E. 2017. Climate change and biological invasions: evidence, expectations, and 508 response options. Biological Reviews 92:1297-1313.

509 Janion-Scheepers, C., L. Phillips, C. M. Sgrò, G. A. Duffy, R. Hallas, and S. L. Chown. 2017.

510 Basal resistance enhances warming tolerance of alien over indigenous species across latitude.

511 Proceedings of the National Academy of Sciences 115:145-150.

512 Jeschke, J. M., and D. L. Strayer. 2005. Invasion success of vertebrates in Europe and North 513 America. Proceedings of the National Academy of Sciences of the United States of America $514 \quad 102: 7198-7202$.

515 Kingsolver, J. G., S. E. Diamond, and L. B. Buckley. 2013. Heat stress and the fitness 516 consequences of climate change for terrestrial ectotherms. Functional Ecology 27:14155171423.

518 Koch, L. K., and J. Meunier. 2014. Mother and offspring fitness in an insect with maternal 519 care: phenotypic trade-offs between egg number, egg mass and egg care. BMC evolutionary 520 biology 14:125.

521 Kohlmeier, P., K. Holländer, and J. Meunier. 2016. Survival after pathogen exposure in 522 group-living insects: don't forget the stress of social isolation! Journal of Evolutionary 
524 Kölliker, M. 2007. Benefits and costs of earwig ( $<\mathrm{i}>$ Forficula auricularia $<\mathrm{i} />)$ family life.

525 Behavioral Ecology and Sociobiology 61:1489-1497.

526 Kölliker, M., S. Boos, J. W. Y. Wong, L. Röllin, D. Stucki, S. Raveh, M. Wu, and J.

527 Meunier. 2015. Parent-offspring conflict and the genetic trade-offs shaping parental

528 investment. Nature communications 6:6850.

529 Körner, M., J. M. Diehl, and J. Meunier. 2016. Growing up with feces: benefits of allo530 coprophagy in families of the European earwig. Behavioral Ecology 27:1775-1781.

531 Körner, M., S. Foitzik, and J. Meunier. 2018. Extended winters entail long-term costs for 532 insect offspring reared in an overwinter burrow. Journal of Thermal Biology 74:116-122.

533 Kramer, J., and J. Meunier. 2016. Maternal condition determines offspring behavior toward

534 family members in the European earwig. Behavioral Ecology 27:494-500.

535 Kramer, J., J. Thesing, and J. Meunier. 2015. Negative association between parental care and 536 sibling cooperation in earwigs: a new perspective on the early evolution of family life?

537 Journal of Evolutionary Biology 28:1299-1308.

538 Lamb, R. J. 1976. Parental behavior in the dermaptera with special reference to Forficula 539 auricularia (Dermaptera: Forficulidae). Canadian Journal of Entomology 108:609-619.

540 Lamb, R. J., and W. G. Wellington. 1975. Life history and population characteristics of the 541 european earwig, Forficula auricularia (Dermaptera: forficulidae), at Vancouver, British 542 columbia. Canadian Journal of Entomology 107:819-824.

543 Levis, N. A., and D. W. Pfennig. 2016. Evaluating "Plasticity-First" Evolution in Nature:

544 Key Criteria and Empirical Approaches. Trends in Ecology and Evolution 31:563-574.

545 Meehl, G. A., and C. Tebaldi. 2004. More Intense, More Frequent, and Longer Lasting Heat 
Waves in the 21st Century. Science 305:994-997.

547 Merilä, J., and A. P. Hendry. 2014. Climate change, adaptation, and phenotypic plasticity:

548 The problem and the evidence. Evolutionary Applications 7:1-14.

549 Meunier, J., J. W. Y. Wong, Y. Gómez, S. Kuttler, L. Röllin, D. Stucki, and M. Kölliker.

550 2012. One clutch or two clutches? Fitness correlates of coexisting alternative female life-

551 histories in the European earwig. Evolutionary Ecology 26:669-682.

552 Van Meyel, S., S. Devers, and J. Meunier. 2019. Love them all: mothers provide care to 553 foreign eggs in the European earwig Forficula auricularia. Behavioral Ecology.

554 Miller, J. S., and A. G. Zink. 2012. Parental care trade-offs and the role of filial cannibalism 555 in the maritime earwig, Anisolabis maritima. Animal Behaviour 83:1387-1394.

556 Moerkens, R., H. Leirs, G. Peusens, T. Beliën, and B. Gobin. 2012. Natural and human 557 causes of earwig mortality during winter: Temperature, parasitoids and soil tillage. Journal of 558 Applied Entomology 136:490-500.

559 Nylin, S., and K. Gotthard. 1998. Plasticity in life-history traits. Annual review of 560 entomology 43:63-83.

561 Paaijmans, K. P., R. L. Heinig, R. A. Seliga, J. I. Blanford, S. Blanford, C. C. Murdock, and

562 M. B. Thomas. 2013. Temperature variation makes ectotherms more sensitive to climate 563 change. Global Change Biology 19:2373-2380.

564 Parmesan, C. 2006. Ecological and evolutionary responses to recent climate change. Annual 565 Review of Ecology, Evolution, and Systematics 37:637-669.

566 Polidori, C., C. Gutiérrez-Cánovas, E. Sánchez, J. Tormos, L. Castro, and D. Sánchez567 Fernández. 2019. Climate change-driven body size shrinking in a social wasp. Ecological 568 Entomology:een.12781. 
570 invasion biology of the invasive earwig, Forficula auricularia in Australasian ecosystems.

571 Biological Invasions 20:1553-1565.

572 Quarrell, S. R., N. W. Davies, P. W. Walker, R. Corkrey, J. A. Smith, and G. R. Allen. 2016.

573 Identification of the putative aggregation pheromone components emitted by the European

574 earwig, Forficula auricularia. Chemoecology.

575 Ratz, T., J. Kramer, M. Veuille, and J. Meunier. 2016. The population determines whether

576 and how life-history traits vary between reproductive events in an insect with maternal care.

577 Oecologia 182:443-452.

578 Rohner, P. T., J. Roy, M. A. Schäfer, W. U. Blanckenhorn, and D. Berger. 2019. Does

579 thermal plasticity align with local adaptation? An interspecific comparison of wing

580 morphology in sepsid flies. Journal of Evolutionary Biology 32:463-475.

581 Sandrin, L., J. Meunier, S. Raveh, J.-C. Walser, and M. Kölliker. 2015. Multiple paternity

582 and mating group size in the European earwig, Forficula auricularia. Ecological Entomology

$583 \quad 40: 159-166$.

584 Singh, S., G. Mishra, and Omkar. 2018. Plasticity in reproductive output and development in

585 response to thermal variation in ladybird beetle, Menochilus sexmaculatus. Journal of

586 Thermal Biology 71:180-188.

587 Smiseth, P. T. 2014. Parental care. Pages 221-242 in D. M. Shuker and L. W. Simmons,

588 editors. The evolution of insect mating systems. Oxford University Press, Oxford.

589 Stoks, R., A. N. Geerts, and L. De Meester. 2014. Evolutionary and plastic responses of

590 freshwater invertebrates to climate change: Realized patterns and future potential.

591 Evolutionary Applications 7:42-55.

592 Thesing, J., J. Kramer, L. K. Koch, and J. Meunier. 2015. Short-term benefits, but 
transgenerational costs of maternal loss in an insect with facultative maternal care.

594 Proceedings of the Royal Society B: Biological Sciences 282:20151617.

595 Tourneur, J.-C. 2017. Epigeal phase of the biological cycle of Forficula auricularia Linnaeus

596 (Dermaptera: Forficulidae) in eastern Canada. Canadian Entomologist 149:600-606.

597 Tourneur, J.-C. 2018. Factors affecting the egg-laying pattern of Forficula auricularia

598 (Dermaptera: Forficulidae) in three climatologically different zones of North America.

599 Canadian Entomologist 150:511-519.

600 Tourneur, J.-C., and J. Gingras. 1992. Egg laying in a northeastern north american (Montréal,

601 Québec) population of Forficula auricularia L. (Dermaptera: Forficulidae). Canadian

602 Entomologist 124:1055-1061.

603 Vancassel, M. 1984. Plasticity and Adaptive Radiation of Dermapteran Parental Behavior:

604 Results and Perspectives. Advances in the Study of Behavior 14:51-80.

605 Vancassel, M., and M. Foraste. 1980. Le comportement parental des Dermaptères. Reprod. 606 Nutr. Dévelop. 20:759-770.

607 Vogelweith, F., S. Foitzik, and J. Meunier. 2017. Age, sex, mating status, but not social 608 isolation interact to shape basal immunity in a group-living insect. Journal of Insect 609 Physiology 103:64-70.

610 Walker, K. A., T. H. Jones, and R. D. Fell. 1993. Pheromonal basis of aggregation in 611 european earwig, Forficula auricularia L. (Dermaptera: Forficulidae). Journal of Chemical 612 Ecology 19:2029-2038.

613 Weiß, C., J. Kramer, K. Holländer, and J. Meunier. 2014. Influences of relatedness, food

614 deprivation, and sex on adult behaviors in the group-living insect Forficula auricularia.

615 Ethology 120:923-932. 
616 Williams, C. M., G. J. Ragland, G. Betini, L. B. Buckley, Z. A. Cheviron, K. Donohue, J.

617 Hereford, M. M. Humphries, S. Lisovski, K. E. Marshall, P. S. Schmidt, K. S. Sheldon, Ø.

618 Varpe, and M. E. Visser. 2017. Understanding evolutionary impacts of seasonality: An

619 introduction to the symposium. Integrative and Comparative Biology:1-13.

620 Williams, J. W., S. T. Jackson, and J. E. Kutzbach. 2007. Projected distributions of novel and

621 disappearing climates by 2100 AD. Proceedings of the National Academy of Sciences $622 \quad 104: 5738-5742$.

623 Wirth, T., R. Le Guellec, M. Vancassel, and M. Veuille. 1998. Molecular and reproductive

624 characterization of sibling species in the european earwig (Forficula auricularia). Evolution $625 \quad 52: 260$

626 Wong, J. W. Y., and M. Kölliker. 2014. Effects of food restriction across stages of juvenile

627 and early adult development on body weight, survival and adult life history. Journal of 628 evolutionary biology 27:2420-30.

629 Zhang, Y.-B., G.-F. Zhang, W.-X. Liu, and F.-H. Wan. 2019. Continuous heat waves change 630 the life history of a host-feeding parasitoid. Biological Control 135:57-65.

633 The complete data set and $\mathrm{R}$ script are archived in the open data repository Zenodo: 634 https://doi.org/10.5281/zenodo.2652192. 
636 Table 1 - Details of the 19 sampled populations. The table shows the name and location of

637 each population, their GPS coordinates (Latitude, Longitude), samplings years, total number

638 of mating pair setup across years (N. pairs), and seasonal temperature variation (defined as

$639 \mathrm{PC} 1, \mathrm{PC} 2$ and PC3).

State (USA)/Province

Populations Country

Asheville USA

Charlestown USA

Deschutes USA

Enderby CDN

Ennis lake USA

Kimberley CDN

Kingston USA

Montreal

Pointe Pelée

Revelstoke CDN

Rocky knob USA

Saluda USA

Santa Cruz* USA

Selkirk CDN

Selinsgrove USA

Truro CDN

Vancouver CDN

Waterrock

knob

Wheatley (CDN)

North Carolina
Rhode Island
Oregon

British Columbia

Montana

British Columbia

Rhode Island

Quebec

Ontario

British Columbia

Virginia

North Carolina

California

Ontario

Pennsylvania

Nova Scotia

British Columbia

North Carolina

Ontario
N. \begin{tabular}{lrcrrrr}
\multicolumn{2}{l}{ Latitude Longitude } & Samplings & pairs & PC1 & PC2 & PC3 \\
\hline 35.612 & -82.566 & $1994-95$ & 80 & 4.60 & 0.73 & 0.74
\end{tabular}

$\begin{array}{lllllll}41.383 & -71.642 & 1990 & 42 & 1.37 & 0.73 & -0.84\end{array}$

$\begin{array}{lllllll}44.157 & -121.256 & 1990 & 17 & -1.54 & -2.32 & -0.27\end{array}$

$\begin{array}{lllllll}50.551 & -119.14 & 1989-90 & 121 & -1.68 & -0.02 & 1.14\end{array}$

$\begin{array}{llllllll}45.447 & -111.695 & 1990 & 36 & -2.86 & -0.36 & 0.02\end{array}$

$\begin{array}{llllllll}49.635 & -115.998 & 1990 & 94 & -5.27 & -0.95 & 0.73\end{array}$

$\begin{array}{lllllll}41.486 & -71.531 & 1991 & 137 & 1.00 & 0.76 & -0.75\end{array}$

$\begin{array}{lccccccc}45.542 & -73.893 & \begin{array}{c}1988,1990- \\ 95\end{array} & 356 & -2.78 & 2.32 & -0.07\end{array}$

$\begin{array}{lllllll}41.963 & -82.518 & 1992 & 47 & 1.25 & 2.31 & -0.37\end{array}$

$\begin{array}{llllllll}50.998 & -118.196 & 1989-90 & 100 & -2.69 & -0.11 & 0.95\end{array}$

$\begin{array}{llllllll}36.832 & -80.345 & 1993-94 & 304 & 1.44 & -0.07 & 0.48\end{array}$

$\begin{array}{lllllll}35.198 & -82.353 & 1993-95 & 117 & 5.03 & 0.69 & 0.77\end{array}$

$\begin{array}{llllllll}36.926 & -121.845 & 1991 & 130 & 5.04 & -4.50 & -0.57\end{array}$

$\begin{array}{lllllll}42.834 & -79.932 & 1992-94 & 233 & -0.69 & 1.35 & -0.67\end{array}$

$\begin{array}{llllllll}40.832 & -76.872 & 1993-94 & 134 & 1.76 & 1.83 & 0.27\end{array}$

$\begin{array}{lllllll}45.372 & -63.264 & 1988 & 39 & -3.46 & -0.13 & -1.42\end{array}$

$\begin{array}{lllllll}49.252 & -123.24 & 1989,1991 & 84 & 0.23 & -2.89 & -0.05\end{array}$

$\begin{array}{lllllll}35.464 & -83.138 & 1991-94 & 167 & -1.88 & -1.69 & 0.22\end{array}$

$\begin{array}{lllllll}42.094 & -82.445 & 1992 & 52 & 1.13 & 2.31 & -0.31\end{array}$

* This population was called San Francisco in (Tourneur 2018). 
640 Table 2 - Loadings of the four first principal components (PCs) reflecting combinations

641 of the $\mathbf{1 2}$ mean monthly temperatures across populations. The traits having significant 642 loadings on each PC are in bold.

\begin{tabular}{ccccc} 
& PC1 & PC2 & PC3 & PC4 \\
\hline Jan & $\mathbf{0 . 8 0 0}$ & -0.589 & -0.066 & 0.083 \\
Feb & 0.716 & $\mathbf{- 0 . 6 6 8}$ & 0.131 & 0.139 \\
Mar & $\mathbf{0 . 8 4 4}$ & -0.486 & 0.216 & 0.048 \\
Apr & $\mathbf{0 . 9 4 9}$ & -0.140 & $\mathbf{0 . 2 6 7}$ & -0.082 \\
May & $\mathbf{0 . 8 9 0}$ & 0.321 & $\mathbf{0 . 2 8 6}$ & $\mathbf{- 0 . 1 4 5}$ \\
Jun & 0.731 & $\mathbf{0 . 6 6 5}$ & 0.123 & -0.060 \\
Jul & 0.547 & $\mathbf{0 . 8 2 3}$ & -0.006 & $\mathbf{0 . 1 4 3}$ \\
Aug & 0.641 & $\mathbf{0 . 7 4 6}$ & -0.013 & $\mathbf{0 . 1 7 5}$ \\
Sep & $\mathbf{0 . 9 0 5}$ & 0.380 & -0.175 & -0.019 \\
Oct & $\mathbf{0 . 9 5 1}$ & 0.019 & $\mathbf{- 0 . 2 9 2}$ & -0.064 \\
Nov & $\mathbf{0 . 9 3 1}$ & -0.174 & $\mathbf{- 0 . 2 9 6}$ & -0.112 \\
Dec & $\mathbf{0 . 8 7 2}$ & -0.469 & -0.113 & 0.041 \\
\hline Eigenvalues & 8.153 & 3.224 & 0.453 & 0.130 \\
Variance explained (\%) & $\mathbf{6 7 . 9}$ & 26.9 & 3.8 & 1.1 \\
Cumulative variance explained & & & & \\
(\%) & 67.9 & 94.8 & 98.6 & 99.7 \\
\hline
\end{tabular}


647 Model estimates (estim).

\begin{tabular}{|c|c|c|c|c|c|c|c|c|c|c|c|c|}
\hline & \multicolumn{4}{|c|}{ PC1 } & \multicolumn{4}{|c|}{ PC2 } & \multicolumn{4}{|c|}{ PC3 } \\
\hline & estim. & SE & $\mathrm{P}$ & adj-P & estim. & SE & $\mathrm{P}$ & adj-P & estim. & SE & $\mathrm{P}$ & adj-P \\
\hline \multicolumn{13}{|l|}{ First clutch } \\
\hline Egg laying date & -1.55 & 1.47 & 0.307 & 0.665 & -8.92 & 2.34 & 0.002 & 0.011 & 20.37 & 6.23 & 0.005 & 0.014 \\
\hline Egg number & -0.32 & 0.82 & 0.705 & 0.896 & 1.87 & 1.30 & 0.171 & 0.234 & -11.77 & 3.47 & 0.004 & 0.014 \\
\hline Egg development time & -0.31 & 0.53 & 0.575 & 0.896 & 2.16 & 0.85 & 0.022 & 0.041 & -4.57 & 2.26 & 0.061 & 0.132 \\
\hline Larvae number & -1.28 & 0.72 & 0.098 & 0.425 & 1.53 & 1.08 & 0.180 & 0.234 & -3.85 & 3.39 & 0.275 & 0.357 \\
\hline \multicolumn{13}{|l|}{ Second clutch } \\
\hline Egg laying date & 0.79 & 2.01 & 0.700 & 0.896 & -3.28 & 3.26 & 0.331 & 0.391 & 13.13 & 8.46 & 0.143 & 0.233 \\
\hline Egg number & 0.08 & 0.44 & 0.855 & 0.896 & -1.97 & 0.72 & 0.016 & 0.041 & 0.27 & 1.86 & 0.887 & 0.887 \\
\hline Egg development time & 1.92 & 0.92 & 0.059 & 0.381 & 3.93 & 1.48 & 0.021 & 0.041 & -19.02 & 4.04 & 0.001 & 0.005 \\
\hline Larvae number & -0.05 & 0.38 & 0.896 & 0.896 & -1.70 & 0.59 & 0.012 & 0.041 & 2.96 & 1.78 & 0.121 & 0.224 \\
\hline \multicolumn{13}{|l|}{ General } \\
\hline Total egg number & 0.17 & 1.01 & 0.866 & 0.896 & -0.15 & 1.60 & 0.929 & 0.929 & -13.93 & 4.26 & 0.005 & 0.014 \\
\hline Total larvae number & -1.04 & 0.77 & 0.198 & 0.642 & 0.60 & 1.16 & 0.615 & 0.666 & -3.45 & 3.61 & 0.355 & 0.419 \\
\hline Ratio of iteroparous females & 0.01 & 0.09 & 0.896 & 0.896 & -0.35 & 0.13 & 0.022 & 0.041 & -0.48 & 0.40 & 0.254 & 0.357 \\
\hline Male longevity & -10.26 & 3.63 & 0.013 & 0.165 & -23.93 & 5.77 & 0.001 & 0.011 & 65.49 & 15.39 & 0.001 & 0.005 \\
\hline Female longevity & -4.30 & 3.74 & 0.268 & 0.665 & -14.80 & 5.94 & 0.025 & 0.041 & 13.63 & 15.86 & 0.404 & 0.437 \\
\hline
\end{tabular}




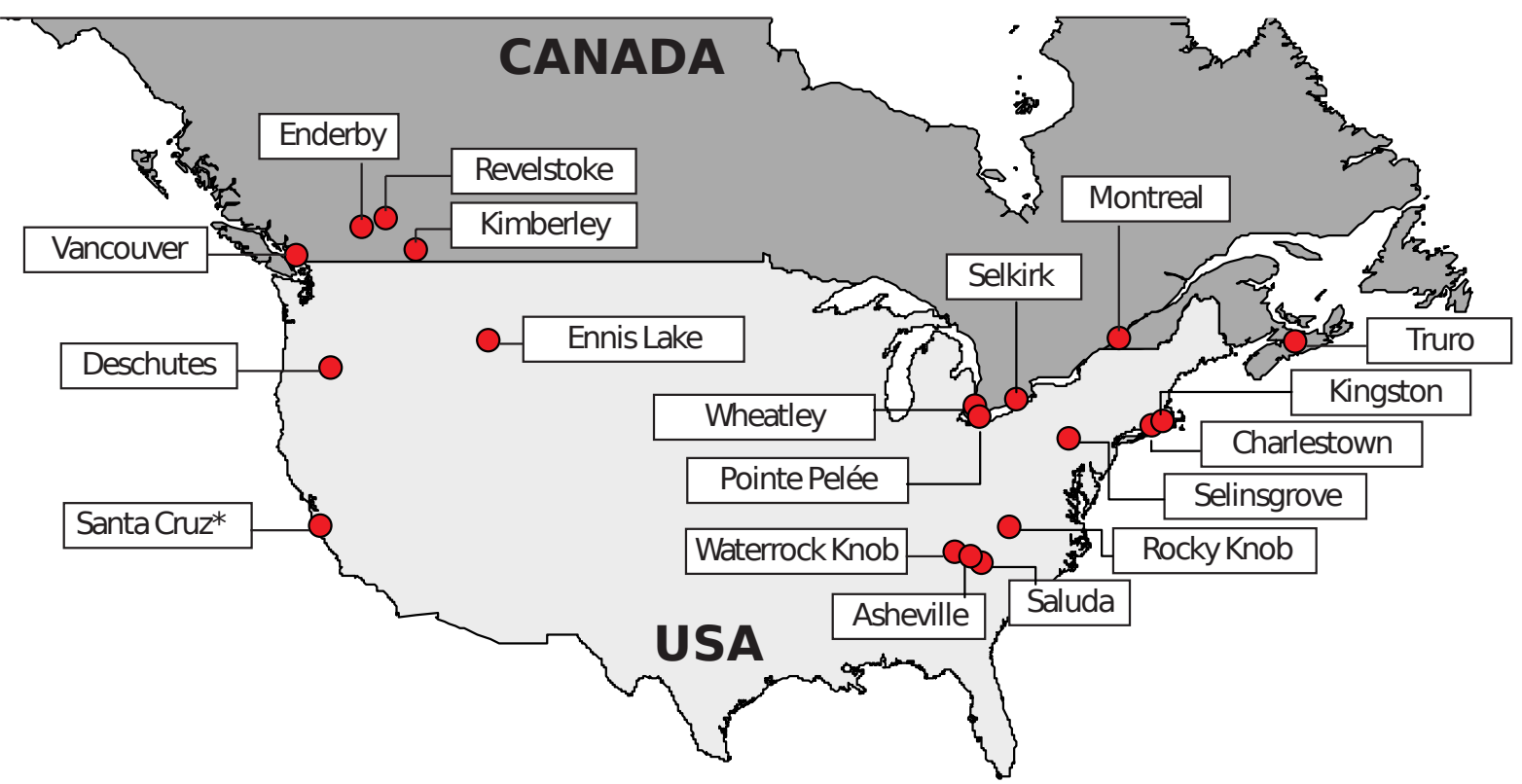

649 Figure 1 - Map showing the 19 sampled populations across Canada (CND) and United States 650 of America (USA). * This population was called San Francisco in Tourneur (2018). 

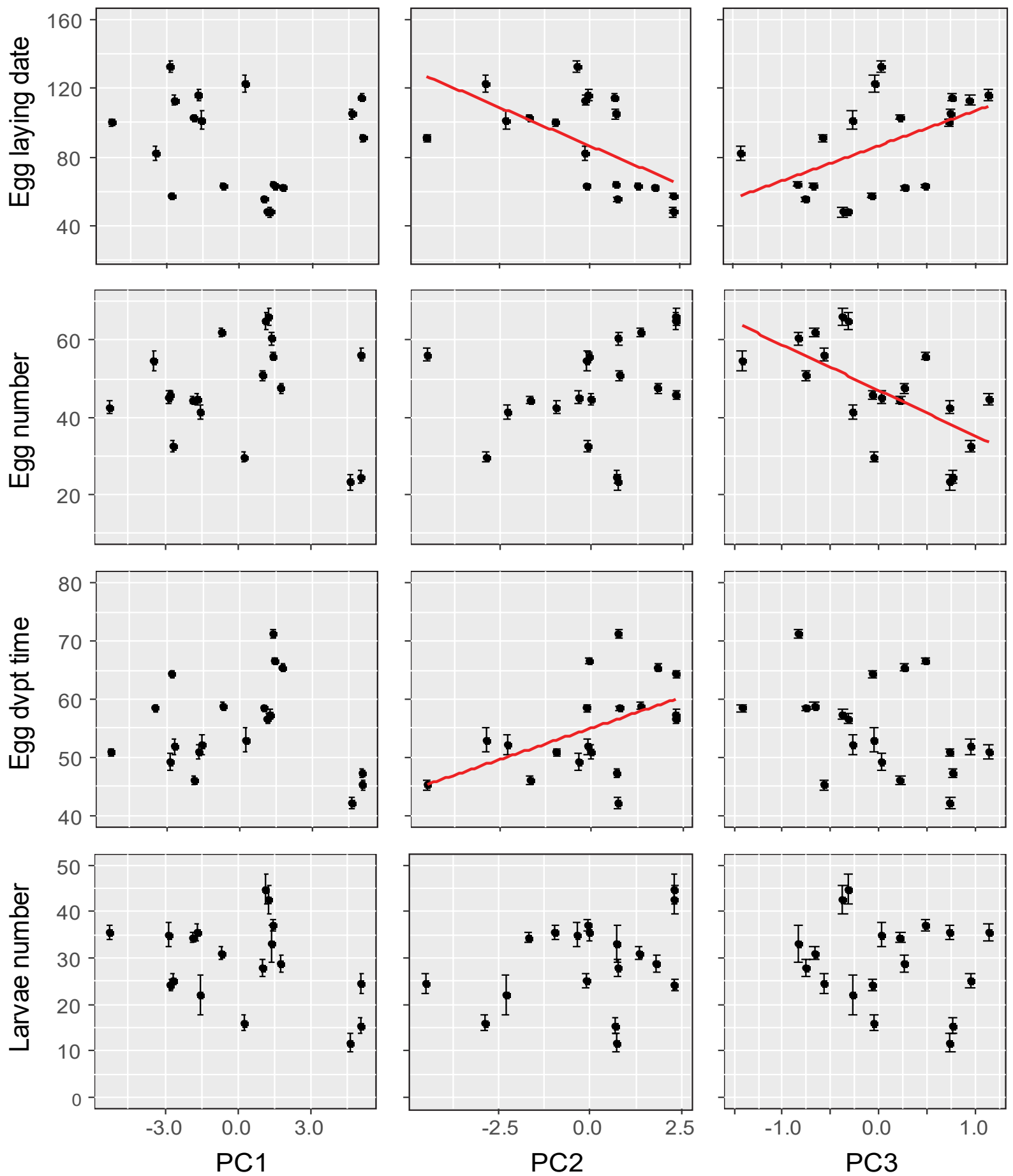

652 Figure 2 - Associations between variation in seasonal temperatures (PC1, PC2, PC3) of the

65319 populations of origin and $1^{\text {st }}$ clutch parameters. Red lines represent correlations significant 654 after FDR correction. Mean values \pm SE. Egg laying date was calculated using October ${ }^{1 s t}$ as a 655 reference (i.e. as day 0$)$. 

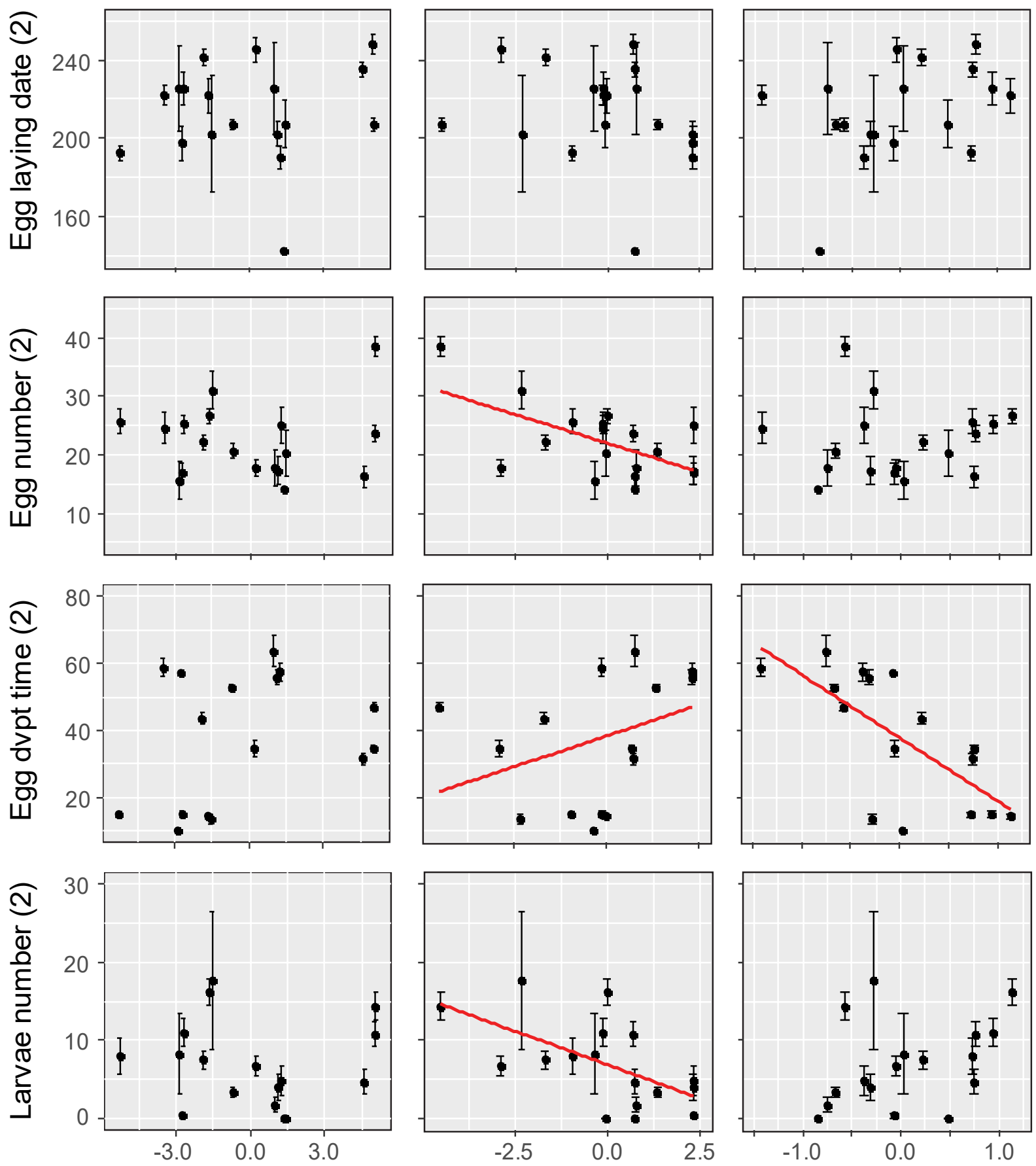

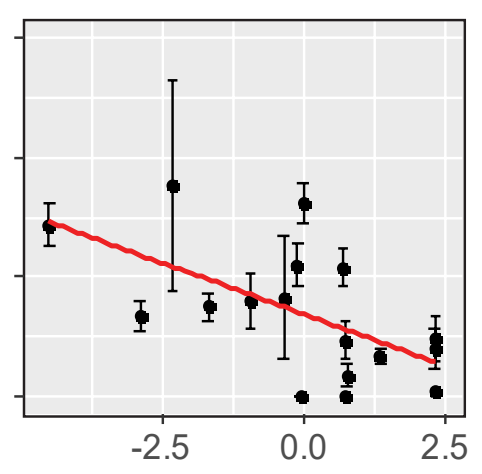

PC2

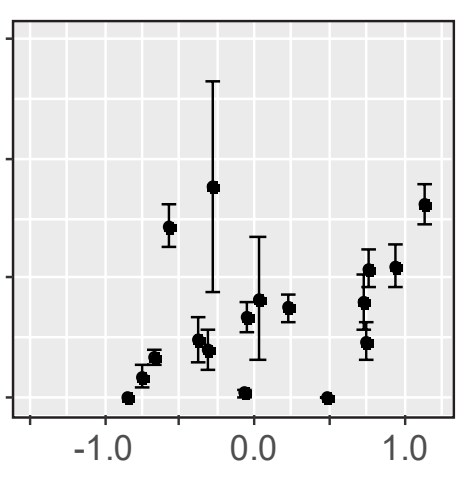

PC3

658 Figure 3 - Associations between variation in seasonal temperatures (PC1, PC2, PC3) of the 65919 populations of origin and $2^{\text {nd }}$ clutch parameters (when produced). Red lines represent 660 correlations significant after FDR correction. Mean values \pm SE. Egg laying date was 661 calculated using October $1^{\text {st }}$ as a reference (i.e. as day 0 ). 

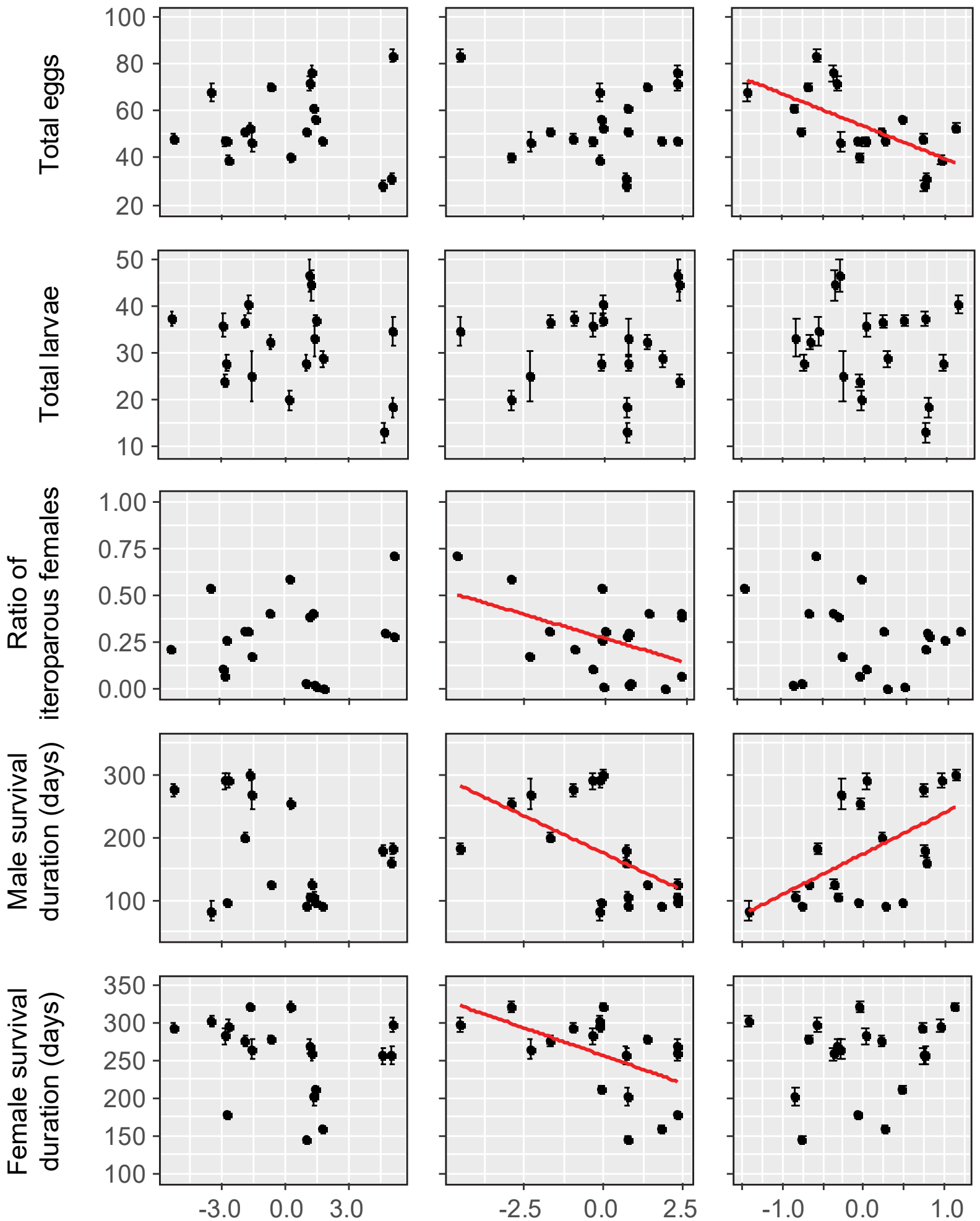

662
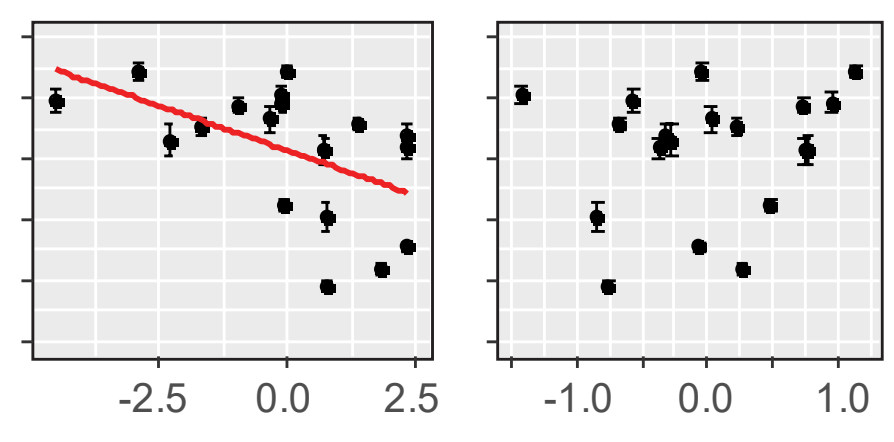

PC2

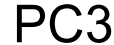

663 Figure 4 - Associations between variation in seasonal temperatures (PC1, PC2, PC3) of the

66419 populations of origin and females' reproductive strategies and outcomes, as well as adult's 665 survival duration. Red lines represent correlations significant after FDR correction. Mean 666 values $\pm \mathrm{SE}$. 